\title{
Escavações para lidar com as ruínas e os soterramentos decorrentes do trauma colonial
}

\section{Excavations to deal with the ruins and burials resulting from the colonial trauma}

DOI:10.12957/ek.2019.48543

Dra. Angela Donini
necadonini@hotmail.com
Professora adjunta no Departamento de Filosofia
Universidade Federal do Estado do Rio de Janeiro [UNIRIO]

Este ensaio problematiza as relações entre ontologia e corpo, considerando que a invenção de ambos se articula por meio do racismo, do eurocentrismo, do capitalismo e da colonialidade. As práticas sustentadas a partir de tais relações vêm atuando de maneira brutal nos corpos definidos como "Outros" e se converteram no eixo organizador da topologia central implicada na categorização da vida. Tal movimento opera por meio de dispositivos ligados às práticas de marcação, exclusão e violência cujos efeitos têm gerado soterramentos contínuos de povos, culturas e práticas. Trabalhar as compreensões de si elaborando os efeitos conscientes e inconscientes de tais marcações pode colaborar para a construção de cosmopercepções advindas de movimentos capazes de acessar as experiências soterradas e ativá-las como guiança.

PALAVRAS-CHAVE Colonialidade. Corpo. Ontologia

This essay problematizes the relationships between ontology and the body, considering the invention of both as articulated through racism, eurocentrism, capitalism and coloniality. The practices sustained by these relationships have been brutally applied to bodies defined as "Others" and consolidated as one of the organizing pillars of the primary topology of the categorization of life. This movement operates through devices linked to practices of labeling, exclusion and violence whose effects have generated the continued burials of peoples, cultures and practices. Working on self understandings through the elaboration of the conscious and unconscious effects of such markings can contribute to constructing cosmo-perceptions that come from movements able to access buried experiences and activate them as guides. 
Este ensaio problematiza as relações entre ontologia e corpo, considerando que a invenção de ambos se articula por meio do racismo, do eurocentrismo, do capitalismo e da colonialidade. As práticas sustentadas a partir de tais relações vêm atuando de maneira brutal nos corpos definidos como "Outros" e se converteram no eixo organizador da topologia central implicada na categorização da vida. Tal movimento opera por meio de dispositivos ligados às práticas de marcação, exclusão e violência cujos efeitos têm gerado soterramentos contínuos de povos, culturas e práticas.

As dinâmicas de categorização da vida se constituíram a partir da diferença colonial e marcam até o presente os fluxos relacionais entre colonialidade, modernidade e capitalismo. Pode-se pensar que a episteme que se estabeleceu a partir do esquadrinhamento praticado pela mirada colonial e sistematizada nos tratados filosóficos, médicos, psicológicos e sociológicos decorre de um processo de reconhecimento e negação, ou seja, uma ontologia que se constitui apenas por meio de uma dinâmica de espelho da branquidade. De acordo com Frantz Fanon (2018), qualquer ontologia se torna irrealizável em uma sociedade colonizada e civilizada. Ele destaca ainda, que, "aos olhos do branco, o negro não tem resistência ontológica". (FANON, 2018, p. 104)

Desobstruir os bloqueios causados pelos efeitos conscientes e inconscientes de tais marcações pode colaborar para a construção de cosmopercepções sensíveis e atentas aos movimentos que se diferem daqueles orquestrados pelas imposições formatadas nos violentos laboratórios da indústria colonial. Essa busca pode ser pensada a partir do modo como ativamos uma espécie de bússola ética (ROLNIK, 2019) de nossas guianças na construção de perspectivas feministas anticoloniais e descoloniais.

Há dois movimentos que me interessam analisar criticamente, um destes movimentos diz respeito à própria constituição ontológica responsável pela consolidação de um ser e o apagamento de todes "Outres". O outro movimento diz respeito ao modo como tal ontologia contribuiu para a constituição de uma noção de corpo para aqueles que não foram circunscritos no escopo da humanidade. O situar de um corpo no mundo é todo ele atravessado pelo direcionamento específico de marcadores estabelecidos para operarem no que se definiu como "Outro".

Para Maria Lugones (2019) tornar colonizades em seres humanos não foi a meta colonial, a modernidade colonial tem como centralidade a dicotomia hierárquica entre humano e não humano, estratégia que obviamente funciona a serviço do homem ocidental. Lugones destaca também que essa imposição vem 
acompanhada de outras distinções hierárquicas, incluindo aquela entre homens e mulheres.

Se considerarmos que a construção de corpo vai decorrer de tal processo e que os passos trilhados no intenso trabalho do dualismo ontológico - responsável por considerar mente e corpo como substâncias distintas - se articulam a este sentido, pode-se pensar em uma hermenêutica do corpo reconhecendo que sua concepção é um marcador central na dinâmica colonialidade-modernidade-capitalismo. O penso, logo existo só pode ocorrer a partir de uma operação que a antecede em 150 anos, trata-se do conquisto, logo existo (DUSSEL, 2005). Assim, o corpo que não existe ontologicamente se converte em um corpo que precisa ser manejado à sua revelia.

\begin{abstract}
A “missão civilizatória” colonial foi a máscara eufemística do acesso brutal aos corpos das pessoas pela exploração inimaginável, violenta violação sexual, controle da reprodução e um horror sistemático (ao dar pessoas vivas para cachorros comerem e ao fazer bolsas e chapéus com as vaginas de mulheres indígenas brutalmente assassinadas, por exemplo). (LUGONES, 2019, p. 360)
\end{abstract}

Vale destacar que tal análise implica partir de um entendimento de que os modos de subjetivação articulados nesta constituição de corpo advêm do trabalho feito em um sistema que atua a partir de mecanismos ligados ao processo de racialização e gendramento de culturas, corpos e territórios, assim como de opressão e silenciamento frente às experiências espirituais. Ele é responsável pela colonização do imaginário e pela constituição de uma geopolítica do conhecimento e hierarquização dos saberes, tendo soterrado memórias vivas com o intuito de silenciar possíveis conexões em nossa psique.

Em tal dinâmica os privilégios se constituíram e ainda se constituem às custas de genocídios, o Ser forjado na história da filosofia europeia é um Ser que tem como base o gesto do extermínio. Trata-se de uma existência que se põe em ação a partir de uma prerrogativa anterior - o extermínio do "Outro" é a condição para se constituir o Ser - vale destacar que esse extermínio ocorre em práticas de violência física, mas também psicológica, ele opera tanto nas dimensões visíveis quanto nas invisíveis.

Grada Kilomba (2019) aponta que no colonialismo há a implementação de um senso de mudez e medo, os efeitos de tal prática precisam ser considerados 
quando pensamos nos modos como nossa capacidade de imaginar e agir frente ao racismo está constituída e nos perguntar que atitudes práticas ainda são necessárias para desobstruir os aprisionamentos materiais e simbólicos gerados pelo trauma colonial decorrente da negação do branco em assumir o roubo colonial, a interdição do presente, o sequestro do futuro e a imposição de seu mundo como universal. (...) a máscara representa o colonialismo como um todo, simbolizando políticas sádicas de conquista e dominação e um regime brutal de silenciamento da/dos chamadas/os outras/os. (KILOMBA, 2019, p.33)

Um dos aspectos trabalhados por Grada nos auxilia na compreensão da negação constitutiva da branquidade no colonialismo, trata-se da inversão perversa acerca do desejo de possuir algo.

\footnotetext{
Embora a plantação e seus frutos, de fato, pertençam "moralmente" à/ao colonizada/o, o colonizador interpreta esse fato perversamente, invertendo-o numa narrativa que lê tal fato como roubo. "Estamos levando o que é Delas/es" torna-se "Elas/es estão tomando o que é Nosso." Estamos lidando aqui com um processo de negação, no qual o senhor nega seu projeto de colonização e o impõe à/ao colonizada/o. É justamente esse momento - no qual o sujeito afirma algo sobre a/o "Outra/o" que se recusa a reconhecer em si próprio - que caracteriza o mecanismo de defesa do ego. (id, p. 34)
}

Em diálogo com Fanon, pode-se pensar que a ontologia ocidental somente esteve a serviço daqueles situados na zona de humanidade. Ela não envolve o reconhecimento dos seres afetados pelo projeto colonial moderno, pois justamente o que ela implicou foi em "um processo ativo de redução das pessoas, a desumanização que as qualificam para a classificação, o processo de subjetivação, a tentativa de transformar o colonizado em menos que humano". (LUGONES, 2019, p. 361)

Esse senso de propriedade vai se estender nos sustentáculos capitalísticos, sendo os corpos racializados e gendrados constantemente alvo das investidas disciplinares, são os mesmos corpos que se converterão em propriedade dos senhores da sociedade industrial.

Trata-se de um sistema que se sustenta nas marcações estabelecidas pelo aparato colonial, as categorias utilizadas para marcar gênero e raça, por exemplo, são categorias que agem no sentido de deturpar experiências de vida fora 
dos marcadores hegemônicos. É esse deturpar que retroalimenta o entendimento de vida e, por consequência, aquilo que deve ser desqualificado como vida, incidindo diretamente nos modos de operar das relações sociais, políticas e culturais.

Os imaginários que se constituem a partir de tal relação maquinam o ódio e alimentam o enclausuramento, a autoficção e a autocontemplação do ser branco. Desde esse lugar, as experiências situadas fora desses marcadores não são vistas, portanto, não são consideradas, mas serão sempre marcadas, diagnosticadas e silenciadas. Essa dinâmica impõe uma série de fraturas na experiência vivida, tais fraturas impactam diretamente nos modos de estar no mundo, de sentir e expressar desejos, fazer concessões se torna uma prática para "evitar" os desmoronamentos de si.

Maria Lugones propõe a possibilidade de se pensar no que pode tomar consistência a partir do habitar o lócus fraturado. Penso que um dos conjuros necessários para que se possa vislumbrar a consolidação de táticas de ressignificação da vida tem a ver com o se dar conta das fraturas e dos modos como elas foram geradas. Essa tomada de consciência seria um dos ativadores da bússola ética, no sentido de que ela permite que uma vida possa se desvincular de projeções fantasiosas acerca de seus lugares de pertencimento e ancestralidade. Lugones propõe um local de ancoragem a partir das histórias de resistência na diferença colonial.

Obviamente que tal operação não é nada fácil, pois ela implica em minar o muro branco feito a partir de uma dinâmica responsável por tentativas sucessivas de pôr fim em alguns mundos, algo que continua acontecendo.

O projeto de transformação civilizatória justificou a colonização da memória e, junto dela, a do entendimento das pessoas sobre si mesmas, sobre suas relações intersubjetivas, suas relações com o mundo espiritual, com a terra, com a matéria de sua concepção de realidade, a identidade, e a organização social, ecológica e cosmológica. (id, 2019, p. 361)

Nesse sentido, as práticas e o corpo que reivindicamos precisam ser problematizados a partir de uma escavação mais complexa, atenta ao que Yuderkys Espinosa Miñoso (2019) articula em seu projeto de crítica à razão feminista moderna eurocêntrica, o questionamento sobre os caminhos do feminismo latino-americano: "como documentar as disputas de sentido e a construção de 
hegemonias e contra-hegemonias que derivam dali?’”. (MIÑOSO, 2019, p. 4) Para ela, tal razão também se constitui como uma razão moderna eurocêntrica. Ela parte da constatação de que a razão feminista ainda se apega a determinados preceitos de mundo ligados ao mito moderno e destaca as proposições de Mario Blaser para pensarmos a modernidade.

(...) Mario Blaser propõe pensarmos a modernidade como o estado do ser que é conquistado quando se coloca em cena o mito moderno composto de três linhas básicas: a) a grande separação entre natureza e cultura, b) a diferenciação colonial entre modernos e não modernos, c) uma temporalidade linear e unidirecional que vai do passado ao futuro. (id., 2019, p. 19)

Portanto, estamos diante de um desafio que envolve a constatação de que há compromissos do feminismo com um projeto moderno e eurocêntrico e, do desafio de se pensar em quais são as implicações necessárias para um agir que seja combativo deste projeto e que ao mesmo tempo nos permita escavar até as raízes de nossa sustentação. Considerando, ainda, que tais raízes são rizomáticas, ou seja, se enredam não hierarquicamente, e que a força que nos constitui não será alimentada pela indústria farmacológica ou por doses de salvação e consumo, ela virá dos esforços em nos despirmos do imaginário algoz e perturbador que funciona para aquelas que colocam em suas entranhas o amor pelo poder e a rigidez de ser sem se dar conta do ser para quem, para o quê e com que tipo de alianças.

Gina Valdéz (1982) fala sobre escavação de um modo que me interessa bastante, ela convoca tal procedimento como um movimento de peneirar os ossos, buscar algum tutano neles, pegar alguns e deixar o resto nos seus túmulos. Esse movimento me parece de alguma forma ser uma pista para desobstruir a densidade de lama jogada nos fluxos vitais com o intuito de reprimir e desconsiderar as vidas de muitas mulheres e pessoas trans.

É importante considerarmos que para algumas pessoas não há a constituição de um eu, mas sim de um "Outro", fator determinante de relações que sempre se estabelecem a partir da presença alienante do branco. (KILOMBA, 2019) Então, o trabalho de confronto com essa distinção hierárquica é uma das tarefas a serem empreendidas e ela seguramente exige esforços no sentido de imaginarmos e agirmos para além das amarras dos modos modernos de subjetivação. 
Começando com a colonização das Américas e do Caribe, uma distinção hierárquica e dicotômica entre humanos e não humanos foi imposta sobre os colonizados a serviço do homem ocidental e ela foi acompanhada por outras distinções que obedeciam à mesma lógica, como aquela entre homens e mulheres. Esse tipo de diferenciação se tornou uma marca da humanidade e da civilização (LUGONES, 2019, p. 358)

Um dos efeitos desta marca se situa na construção da noção de corpo, que passa a figurar ao longo dos séculos que se sucederam a essa divisão dicotômica e hierárquica. Assim, o que procuro problematizar aqui está relacionado a um grande tema da filosofia contemporânea e para além dela, em toda sua articulação interdisciplinar com as artes, com a medicina, com a sociologia, etc. Escrever sobre corpo, assim como escrever sobre alteridade, se converteu em uma moda, especialmente no século XX. Vejo a necessidade de nos atentarmos para algumas perguntas: O que significa ter um corpo? Quem tem um corpo? Quem carrega um corpo? Quem pode se expressar pelo corpo? Que corpo é esse de que estamos falando?

Traçar as relações entre a ontologia e a constituição de uma morada chamada corpo dá ao projeto moderno colonial capitalístico uma capacidade de operar por meio de tecnologias múltiplas de manutenção dos procedimentos de controle e usurpação. Torna-se, portanto, urgente organizar a compreensão de que tal dinâmica age materialmente em termos raciais e de gênero na sustentação dos lugares de conforto daqueles que não precisam pensar sua existência no mundo, são alienados e seguem se alienando dela por uma ontologia colonial, mas também por uma corporificação colonial. Esse sistema de larga duração e em guerra permanente, que age no corpo físico e nos corpus sociais demarcados pela diferença colonial, tem sido responsável por violação, exploração, expropriação, extermínio, naturalização da tortura e da morte precoce. A concepção de sociedade que emerge desta dinâmica é constituída por corpos e como corpos. Oyèrónkẹ́ Oyěwùmi destaca a ironia do fato de que "mesmo quando o corpo permanece no centro das categorias e discursos sociopolíticos as pessoas que organizam tais pensamentos negam sua existência para certos grupos de pessoas, inclusive elas mesmas" (OYĚWÙMÍ, 1997, p.4). É fato que a ausência de corpo tem sido uma pré-condição para o pensamento racional, este é um dos aspectos centrais que sustenta tal projeto de mundo. 
Mulheres, primitivos, judeus, africanos, pobres e todas aquelas pessoas que foram qualificadas com o rótulo de "diferente" em épocas históricas variadas foram consideradas corporalizadas, dominadas, portanto, pelo instinto e pelo afeto, estando a razão longe delas, elas são o outro e o outro é um corpo. (Id., 1997, p.4)

Decorrente de tais marcações há um outro movimento, que é a semiotização que constitui um "corpus social". Nossa imaginação está povoada de visualizações específicas e marcadas por estigmas, o que fica colado em nosso imaginário é a divisão de mundos. Oyěwùmi afirma que "ao corpo é dada uma lógica própria. Acredita-se que, ao olhar para ele, pode-se inferir as crenças e a posição social de uma pessoa ou a falta delas". (ibidem, 1997, p.2) Um sintoma permanente deste processo é que sempre e infinitamente os corpos marcados pelas categorias modernas da indústria colonial precisam se justificar, se explicar e se adaptar.

De quem é o corpo que precisa ser infinitamente explicado, detalhado e justificado? Os esforços gigantescos, as elaborações infinitas, estão sempre por conta de classificar, detalhar, esquadrinhar os corpos considerados "Outros". Assim, quem está na situação de conforto apenas assiste, como se estivesse em um parque de diversões, assistindo uma TV, tocando na tela do celular, dando um like, ouvindo um podcast, etc.

Mas porque será que algumas vidas precisam tanto de explicação? Porque tais corpos necessitam de tantas análises? Seria o medo da branquidade de viver a experiência de descentramento? Seria a dificuldade da branquidade de se explicar a si mesma? Ver é ver o corpo, mas que corpo? O corpo marcado, gendrado, racializado.

Depois tivemos de enfrentar o olhar branco. Um peso inusitado nos oprimiu. $\mathrm{O}$ mundo verdadeiro invadia o nosso pedaço. No mundo branco, o homem de cor encontra dificuldades na elaboração de seu esquema corporal. O conhecimento do corpo é unicamente uma atividade de negação. É um conhecimento em terceira pessoa. Em torno do corpo reina uma atmosfera densa de incertezas. (FANON, 2008, p. 104)

O resgate dos soterramentos exige um trabalho capaz de mobilizar a compreensão de aspectos da vida que foram eclipsados para se constituir a narrativa 
de dominância, foram silenciados forçosamente, portanto, tais escavações exigem perspectivar giros de sentido nas narrativas que absorvemos como verdadeiras a respeito dos corpos.

Ativar uma cosmopercepção acerca do corpo em sentido expandido que vibre desde os ecos ancestrais implica manejar os instrumentos físicos e mentais capazes de mover as coisas que foram soterradas e também as que vêm sofrendo forçosos aterramentos, isso implica pensar e se posicionar criticamente às dinâmicas de poder intrínsecas à razão feminista. Isso não tem nada a ver com ir ali viver uma experiência diferente e voltar para a mesma zona de habitação traçada por essa topografia colonial.

Tal deriva desimplicada apenas sustenta a permanência dos mecanismos turísticos de visitas à alteridade, como um ir ali e voltar já, à revelia das trajetórias de vida implicadas no que se chama "alteridade", apenas objetificação e fetichismo. "Naturalmente" a presença do Outro e o corpo do Outro eram vistos como algo existente para servir às finalidades do desejo do homem branco. (hooks, 2019, p. 69)

Para bell hooks, a instrumentalização do corpo "Outro" é situada como um terreno inexplorado, que se converte em solo fértil para a reconstrução da norma masculina. O que decidem é usar o "Outro" como testemunha participante desta transformação.

Sem estarem atentos a determinados aspectos de suas fantasias sexuais que irrevogavelmente os unem à dominação racista coletiva, acreditam que seu desejo por contato representa mudança progressista nas atitudes dos brancos em relação às pessoas não brancas. (hooks, 2019, p. 70)

O modo capitalista colonial de agenciar a vida se organiza a partir desta grande onda que já dura cinco séculos: situar tudo no corpo e considerá-lo como naturalizado ao longo de todo o processo em curso, estratégia necropolítica que se relaciona tanto à espacialização dos corpos quanto aos modos de subjetivação decorrentes de tais dinâmicas.

Vejo que uma das tarefas implicadas em romper com as amarras da razão feminista exige a busca por rupturas com os procedimentos de imaginação e da leitura dos corpos gendrados e racializados a partir das categorizações imagéticas que atuam nos traços da memória colonizada. Com isso, nos vemos diante 
do desafio de não remeter mais a linguagem corporal a objetos enumeráveis e combináveis da ontologia, tampouco a vozes emissoras ligadas a tal dinâmica, mas produzir deslocamentos para lidar com as feridas coloniais. Não que seja possível apagar os efeitos dos traumas, mas sim, no sentido de se trabalhar para que não causem mais danos, isso exige que os sujeitos brancos deixem de ser ativadores de tais feridas, se deem conta da experiência da branquidade e seus efeitos nefastos decorrentes da perpetuação da negação de seus atos e tomem consciência do racismo também como um processo psicológico que exige trabalho (KILOMBA, 2019).

Essa busca implica uma certa escavação, como se nos propuséssemos a olhar para aquilo que se tornou ruína antes mesmo de se estruturar, as ruínas que ficaram por dentro de histórias de vida soterradas. A perda do conhecimento e das práticas das pessoas que estão próximas de nós é um exemplo disso. Fazer com que uma tomada de consciência crítica frente a ideia de progresso nos possibilite constituir visões espiraladas da história para provocarmos aberturas necessárias para a passagem de outros modos de vivenciar os corpos.

Ou seja, a sustentação da compreensão de corpo a partir de imagens alheias ao nosso desejo não é um movimento que surge na contemporaneidade, este movimento apenas se intensifica na medida em que a imagem passa a ser radicalmente presente em nossas vidas como motor tanto das negociações comerciais quanto do capitalismo afetivo.

Ativar uma percepção expandida, desierarquizar do olhar o entendimento de mundo que nos atravessa. Tal hierarquização tem contribuído para sustentar o programa colonial e podemos observar como essa dinâmica foi se firmando como verdade a partir dos discursos dos saberes. Por exemplo, o olhar para os animais a partir da implantação de zoológicos, a histeria e as sessões públicas como um projeto fotográfico, os modos como o racismo sustenta a história ocidental do cinema, as narrativas inventadas para a constituição do repertório imagético de poder, as tecnologias biopolíticas que, ao centrar suas estratégias no corpo, produzem ao mesmo tempo um esvaziamento de sentido do corpo como lócus potencial de acesso de conhecimento para ser repertoriado, tecnologizado, cirurgiado, transformado.

Tomar um sentido interrogativo frente a atitude moderna e transformá-la em problema, não em solução, de modo que, acompanhando Anzaldúa, possamos "articular expressões de dor, confusão, alegria e outras experiências até agora experimentadas em um nível emocional inarticulado". (ANZALDÚA, 2009, p. 122) 
É preciso que tudo o que vem sendo soterrado se desloque do escopo da visão corporalizada desde a ontologia excludente e ganhe autonomia em suas paisagens para percorrer outras vias. Ativar tais forças é parte da invenção de mundos onde caibam todos os mundos soterrados, é na existência mesma que tal processo pode se dar, ele envolve escavações e encontros com frequências que foram silenciadas, anestesiadas, subjugadas e violadas, diz respeito à experimentação que Gloria situa no nível emocional inarticulado.

A partir de nossa própria experiência e das experiências do nosso povo, tentaremos criar imagens e metáforas que nos deem uma sustentação sobre o numinoso, uma estruturação da capacidade de autocura, que pode curar o espírito deprimido, a alma assustada. (id., 2009, p. 122)

Em 2017 pude ver Ana Correa apresentar a peça "Rosa Cuchillo: el desmontaje"1. Ao operar uma dinâmica de desmontagem, os recursos que Ana utiliza desconstroem a linguagem interpretativa e representacional do teatro e transforma-as em uma dinâmica aberta que revela os bastidores, de modo que ali, no mesmo espaço cênico clássico, seja possível vivenciar e compreender todos os detalhes envolvidos na montagem de uma peça teatral, desde a história dos objetos, do figurino, imagens de arquivo, ao mesmo tempo em que ela mesma vai se montando, se maquiando, se vestindo. O procedimento de desmontagem em si expõe o processo criativo em seus detalhes e coloca o contexto cênico em um estado vulnerável, suscetível e poroso. Ali ela compartilhou aspectos do processo de pesquisa, as práticas, técnicas, dúvidas, heranças familiares e artísticas, testemunhos e aprendizado espiritual

Se colocar em desmontagem é uma espécie de liberação da atmosfera das arquiteturas clássicas, feitas para proteger, para não suscitar vulnerabilidades, para apaziguar o risco. Mas também sabemos que nem tudo que se pretende em desmontagem funciona, pois isso vai depender do grau de implicação com tal procedimento e, por outro lado, do quão disponível e em que condições isso é feito.

Um dos aprendizados que levo comigo desta experiência tem a ver com algo

1 Peça teatral do Grupo Yuyachkani, com Ana Correa e direção de Miguel Rubio baseada no livro "Rosa Chuchillo" (2000) que conta a história de Rosa, uma mulher que procura incansavelmente por seu filho desaparecido no meio da guerra com Sendero Luminoso. O espetáculo tornou-se um símbolo da luta e defesa dos direitos humanos no Peru. 
que Ana contou durante a desmontagem: ao falar sobre a perda da língua Quechua por parte de muitas mulheres pelo fato de esconderem tal pertencimento, ela compartilhou algo sobre sua avó, nos disse que sua avó curava sustos. Para sua avó quando há o susto a alma sai da pessoa, ou seja, o trauma te divide, te separa. E ela, já adulta, procurou um mestre em Cusco para poder se curar do susto, diante de tal experiência, segundo ela "foi possível sentir a curação andina, sentir que te tocam, que te bailam, que te colocam flores. As vezes vamos a uma consulta médica e não nos tocam, saímos com uma receita e uma promessa de cura. No curandeiro, na curandeira, saímos diferentes. Com a aura distinta."

\section{Recebido em: 18.02.2020 | Aprovado em: 28.03.2020 $R$ Referência Bibliográfica}

ANZALDÚA, Gloria. The Gloria Anzaldúa Reader. Livro editado por Analouise Keating. Durham, N.C.: Duke University Press, 2009

DUSSEL, Henrique. Europa, modernidad y eurocentrismo. Texto disponível em http://bibliotecavirtual. clacso.org.ar/ar/libros/dussel/artics/europa.pdf.

FANON, Frantz. Pele Negra, Máscaras Brancas. Salvador: EDUFBA, 2008.

HOOKS, bell. Olhares negros. Raça e representação. São Paulo: Elefante, 2019.

KILOMBA, Grada. Memórias da plantação. Episódios de racismo cotidiano. Rio de Janeiro: Cobogó, 2019.

LUGONES, Maria. Rumo a um feminismo descolonial. In: HOLANDA, Heloisa Buarque (org). Pensamento feminista: conceitos fundamentais. Rio de Janeiro: Bazar do tempo, 2019.

MIÑOSO, Yuderkys Espinosa. Fazendo uma genea- logia da experiência: o método rumo a uma crítica da colonialidade da razão feminista a partir da experiência histórica na América Latina. In: HOLANDA, Heloisa Buarque (org). Pensamento feminista hoje: perspectivas decoloniais. Separata. Rio de Janeiro: Bazar do tempo, 2019.

OYĚWÙMI, Oyèrónkẹ'. The Invention of Women: Making an African Sense of Western Gender Discourses. Minneapolis, MN: University of Minnesota Press, 1997. Tradução para uso didático de Wanderson Flor do Nascimento.

ROLNIK, Suely. Esferas da Insurreição: notas para uma vida não cafetinada. São Paulo: n-1 edições, 2018.

VALDÉZ, Gina. Puentes y Fronteras. Los Angeles, Castle Lithograph, 1982.

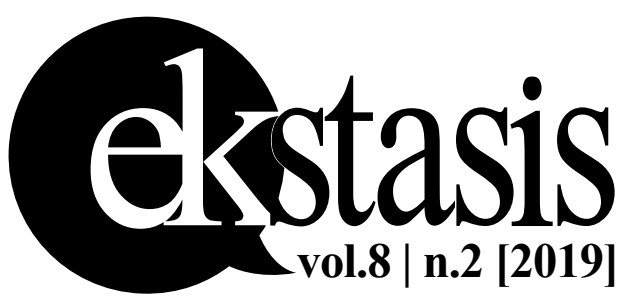

